\title{
Tear hypoxia-inducible factor-1a expression, lactate dehydrogenase, and malate dehydrogenase activity changes in soft contact lens wear
}

\author{
Tri Rahayu, ${ }^{1,2}$ Tjahjono Darminto Gondhowiardjo, ${ }^{1,2}$ Widya Artini, ${ }^{1,2}$ Septelia Inawati Wanandi ${ }^{3}$
}

pISSN: 0853-1773 • elSSN: 2252-8083 https://doi.org/10.13181/mji.oa.203405 Med J Indones. 2020;29:372-8

Received: January 17, 2019

Accepted: September 10, 2020

Authors' affiliations:

'Department of Ophthalmolgy, Faculty of Medicine, Universitas Indonesia, Cipto Mangunkusumo Hospital, Jakarta, Indonesia, 'JEC Hospitals, Jakarta, Indonesia, ${ }^{3}$ Department of Biochemistry and Molecular Biology, Faculty of Medicine, Universitas Indonesia, Jakarta, Indonesia

\section{Corresponding author:}

Tri Rahayu

Department of Ophthalmolgy Faculty of Medicine, Universitas Indonesia, Cipto Mangunkusumo Hospital (RSCM Kirana), Jalan Kimia No. 8-10, Pegangsaan, Menteng, Central Jakarta 10320, DKI Jakarta, Indonesia

Tel/Fax: +62-21-31902885

E-mail: tri_gajahseno@yahoo.com

\begin{abstract}
BACKGROUND Soft contact lens (SCL) wear can lead to a corneal hypoxia. However, there is a lack of studies looking for corneal hypoxia biomarkers in tear. This study aimed to investigate corneal hypoxia among $\mathrm{SCL}$ wearers based on hypoxia-inducible factor$1 a$ (HIF-1a) expression, tear lactate dehydrogenase (LDH), and malate dehydrogenase (MDH) activities.
\end{abstract}

METHODS A nonrandomized clinical trial was conducted on two groups. SCLs were prescribed for 2 months to a group of new wearers. Meanwhile, SCL wear was discontinued for 1 month in a group of long-term wearers. Tear samples were then collected on days $1,7,14,28$, and 56 after treatment. Repeated-measures analysis of variance and Friedman's test with post-hoc statistical analysis were used to evaluate biomolecular changes (HIF-1a concentration, LDH, and MDH activities) in both groups.

RESULTS A total of 14 subjects (28 eyes) were enrolled in each group. In new wearers, there was a significant decrease in MDH level $(p=0.010)$ and no effect on HIF-1a level. In long-term wearers, HIF-1 $\alpha$ and LDH levels tended to decrease $(p=0.054)$. A significant decrease on MDH level was noted on days $7(p=0.003), 14(p=0.026)$, and $28(p<0.010)$. Long-term wearers had a higher LDH baseline level than new wearers ( $p$ $=0.04)$.

CONCLUSIONS Corneal hypoxia was not proven after 2 months of SCL wear using biomarkers. However, LDH and MDH activities in tears were found to be decline after $\mathrm{SCL}$ discontinuation.

KEYWORDS contact lenses, cornea, hypoxia, hypoxia-inducible factor 1, lactate dehydrogenase, malate dehydrogenase
Contact lens has been widely used for vision correction and cosmetic purposes., ${ }^{1,2}$ In 2013, it is estimated that there are more than 140 million contact lens wearers worldwide, and the number is expected to increase. ${ }^{3}$ However, contact lens wear can induce hypoxia in the cornea and lead to many complications as it acts as a barrier to oxygen transportation. ${ }^{1,4}$

Contact lens may decrease oxygen supply to the cornea, depending on oxygen permeability described as oxygen flow velocity (Dk). Oxygen transmissibility, defined as oxygen's ability to move through the thickness of contact lens, is directly proportional to oxygen permeability and inversely proportional to lens thickness $(t)$. Thus, oxygen transmissibility of contact lens is calculated using the following formula: $\mathrm{Dk} / \mathrm{t}^{5-7}$ Long-term use of soft contact lens $(\mathrm{SCL})$ has been known to alter the corneal structure, that is, decreasing epithelial and stromal thickness and increasing endothelial polymegathism and pleomorphism, thereby lowering oxygen uptake rates. The cause of the changes may include contact lens wear-induced hypoxia, which has been found in 
patients who had worn SCL for over a year. ${ }^{7,8}$ Recovery of normal epithelial oxygen uptake can be achieved 1 month after SCL wear cessation. ${ }^{9}$

In human tears, lactate dehydrogenase (LDH) and malate dehydrogenase $(\mathrm{MDH})$ are enzymes produced by the corneal epithelium. Studies have revealed that whenever the eyes are closed for a long time, such as during bedtime, the cornea experiences a relatively hypoxic condition detected by an increase in LDH production in the next morning. In corneal hypoxia, there is also an increase of hypoxia-inducible factor-1 (HIF-1). HIF-1 is a heterodimer protein consisting of two subunits, HIF-1a and HIF-1 $\beta$, which modulate gene expression based on cellular oxygen concentration. In a normal condition, dioxygenases called prolylhydroxylase hydroxylate HIF-1 using oxygen and ketoglutarate as the substrate. Hydroxylation is inhibited in hypoxic condition, causing HIF-1 accumulation. ${ }^{10}$

The use of a biomarker will lead to better detection of corneal hypoxia. There is a lack of studies on biomarkers of corneal hypoxia in tears. This study aimed to investigate corneal hypoxia among $\mathrm{SCL}$ wearers based on tear HIF-1a expression, LDH and MDH activities.

\section{METHODS}

This is a nonrandomized clinical trial on 14 subjects (14 pairs of eyes) at Cipto Mangunkusumo Hospital, Jakarta, who were recruited by consecutive sampling and divided into two groups: new- and long-term wearers of SCL. Samples were taken from January 2015 to December 2016 and analyzed at the Biochemistry Laboratory, Faculty of Medicine Universitas Indonesia. Ethical clearance was obtained from the Ethics Committee of the Faculty of Medicine Universitas Indonesia (No: 800/UN2.F1/ETIK/2015).

\section{Subject groups}

Both groups consisted of subjects aged 18 to 30 years. The new wearer group included those who had moderate myopia with spherical equivalent of -3.00 to -6.00 diopters (D) with astigmatism less than $1.50 \mathrm{D}$, were at least 1 year free from wearing $\mathrm{SCL}$, and agreed to wear SCL for 2 months. The long-term wearer group comprised subjects who wore SCL for at least 1 year and agreed to not wear SCL for 1 month. Subjects who had corneal abnormalities, infectious or active inflammatory diseases, or experienced eye surgery were excluded from the study.

Before SCL fitting and tear sampling, the new wearers underwent refraction examinations using Snellen chart and slit lamp. SCLs used in this study were Alcon DAILIES ${ }^{\circledR}$ AquaComfort PLUS (Nelfilcon A, Alcon Novartis, Switzerland) with Dk of $26 \times 10^{-11}$, water content $69 \%$, thickness $0.10 \mathrm{~mm}$ at $-3.00 \mathrm{D}$. Corneal thickness, endothelial cell density, central corneal endothelial cell size variability, and hexagonality were examined under the Non-Con Robo specular microscope (Konan Medical, Inc., Japan). The subjects were trained to insert and remove the lens. Welltrained subjects were then given logbooks to record the length of wear per day and write any complaints. Subjects were asked to wear SCL for at least 8 hours per day.

\section{Tear collection}

Tear samples were collected from subjects' inferior fornix of both eyes using micropipettes on days 1,7 , 14,28 , and 56 of SCL wear after removing the lenses first. Tear samples from long-term wearers were also collected while they were still wearing their SCL at the same time points. Tear samples were poured into microtubes, covered with aluminium foil, and sealed with semi-transparent, flexible film. Samples were stored at $-80^{\circ} \mathrm{C}$ until used.

\section{Laboratory examinations}

Human HIF-1a Elabscience ${ }^{\circledR}$ enzyme-linked immunosorbent assay (ELISA) kit test (Elabscience Biotechnology Co., Ltd., China) was used with a single-wash 90-min sandwich ELISA designed for the quantitative measurement of HIF-1a protein in human cell extracts. Spectrophotometry with a wavelength of $450 \pm 2 \mathrm{~nm}$ was used to obtain the optical density (OD) value, which was directly proportional to HIF-1a concentration. HIF-1a concentration was calculated by comparing OD to a standard curve.

Quantitative colorimetric kinetic LDH activity determination using QuantiChrom ${ }^{\mathrm{TM}}$ Lactate Dehydrogenase Kit (BioAssay Systems, USA) measured LDH activity. Nonradioactive colorimetric LDH measurement was based on tetrazolium salt 3-(4,5-dimethylthiazol-2-yl)-2,5-diphenyltetrazolium bromide reduction in nicotinamide adenine dinucleotide enzymatic reaction, which has a maximal absorption wavelength of $565 \mathrm{~nm}$. The intensity 
of purple color formed by the reaction is directly proportional to enzyme activity. Meanwhile, the $\mathrm{MDH}$ activity was measured using QuantiChrom ${ }^{\mathrm{TM}}$ Malate Dehydrogenase Kit (BioAssay Systems) with nonradioactive colorimetric measurement similar to the aforementioned LDH activity measurement.

\section{Data analysis}

Data were analyzed using SPSS version 22.0 (IBM Corp., USA). Significance was set at $p<0.05$. Kolmogorov-Smirnov test was used to perform the normality test. Nonparametric data were analyzed using repeated measures analysis of variance, Bonferroni post-hoc test, Friedman's test, and post-hoc Wilcoxon signed-ranked test.

\section{RESULTS}

The characteristics of subjects in the new and longterm wearer groups are shown in Table 1. Figure 1a presents the HIF-1a level in the new wearer group on baseline (day 0 ) and days $1,7,14,28$, and 56 . The HIF-1a level tended to increase on day 1 (mean difference [MD] $=0.061 \mathrm{ng} / \mathrm{mg}$ protein), but no significant increases were found in any time interval compared with the baseline (day $0 ; p=0.193$ ).

The LDH and MDH activities in the new wearer group on days $1,7,14,28$, and 56 showed no significant increase than on baseline ( $p=0.704$; Figure 1b). A significant decrease $(p=0.016)$ was observed in the
MDH level (Figure 1c) instead. The results shown were from sampling on days $7(\mathrm{MD}=-0.03 \mathrm{IU} / \mathrm{mg}$ protein; Bonferroni $p=0.017)$ and $56(\mathrm{MD}=0.11 \mathrm{lU} / \mathrm{mg}$ protein; Bonferroni $p=0.010)$. MDH activity on day 56 also significantly decreased from day $28(M D=0.235, p=$ -0.023).

An increasing trend of $\mathrm{LDH} / \mathrm{MDH}$ ratio was noted from days 1,7 , and 14 to 56 . The increase in LDH/MDH ratio on day 56 was statistically significant than on baseline (day $0 ; \mathrm{MD}=0.09 ; p=0.023$ ).

Tear HIF-1a concentration had a significant positive correlation to $\mathrm{MDH}$ activities at baseline (day $0 ; r=0.507 ; p=0.045)$ and day $28(r=0.508 ; p$ $=0.043)$ with moderate correlation power. HIF-1a concentration also had positive correlations to $\mathrm{MDH}$ activities but were not statistically significant at days 1 $(r=0.364 ; p=0.166), 7(r=0.409 ; p=0.116)$, and $14(r$ $=0.343 ; p=0.193)$. Tear HIF1- $\alpha$ levels in long-term SCL wearers before and after $S C L$ removal are depicted in Figure 1d.

In the long-term wearer group, HIF-1a level and LDH activities (Figure 1, $\mathrm{d}$ and e, respectively) tended to decrease, but this is not statistically significant $(p=$ 0.054). However, MDH activities decreased significantly following SCL removal $(p=0.005)$ as shown in Figure $1 f$. Significant decreases in MDH activities were observed on baseline (day 0$)$ than on days $7(M D=-0.17 ; p=$ $0.003), 14(\mathrm{MD}=-0.23 ; p=0.026)$, and $28(\mathrm{MD}=-0.21$; $p<0.01)$. Unlike in the new wearer group, no significant increases in $\mathrm{LDH} / \mathrm{MDH}$ ratio were found between any

Table 1. Characteristics of subjects using soft contact lens $(\mathrm{N}=28)$

\begin{tabular}{|c|c|c|}
\hline Characteristics & $\begin{array}{c}\text { New wearers, } \\
\text { mean }(S D)(N=14)\end{array}$ & $\begin{array}{l}\text { Long-term wearers, } \\
\text { mean }(S D)(N=14)\end{array}$ \\
\hline Male sex, n (\%) & $7(50)$ & $2(14)$ \\
\hline Age (years)* & $21.0(20.0-24.0)$ & $23.5(2.3)$ \\
\hline Spherical equivalent $(D)^{*}$ & $-4.60(0.94)$ & $-5.12(-3.00--6.00)$ \\
\hline Duration of contact lens wear (years), median (range) & & $5.50(2.00-11.00)$ \\
\hline \multicolumn{3}{|l|}{ Type of soft contact lens, n (\%) } \\
\hline Clear & & $6(42.9)$ \\
\hline Tinted & & $3(21.4)$ \\
\hline Combination & & $5(35.7)$ \\
\hline Corneal thickness $(\mu \mathrm{m})$ & $513.21(31.63)$ & $487.25(28.21)$ \\
\hline Endothelial cell density (cells $/ \mathrm{mm}^{2}$ ) & $2961.07(227.51)$ & $2957.79(283.97)$ \\
\hline Central corneal endothelial cell size variability or coefficient of variation & $41.79(5.80)$ & $44.75(6.07)$ \\
\hline Hexagonality of endothelial cell (\%) & $50.36(10.04)$ & $46.43(7.61)$ \\
\hline
\end{tabular}


a

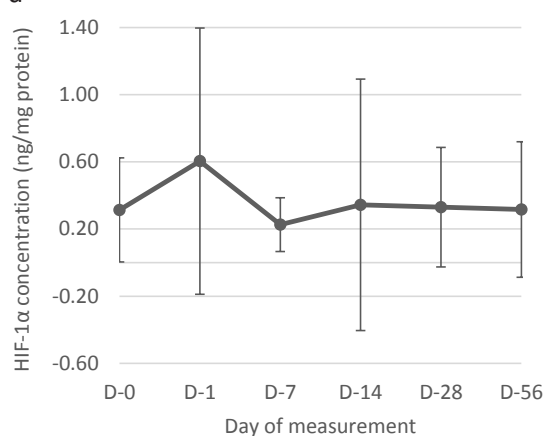

d

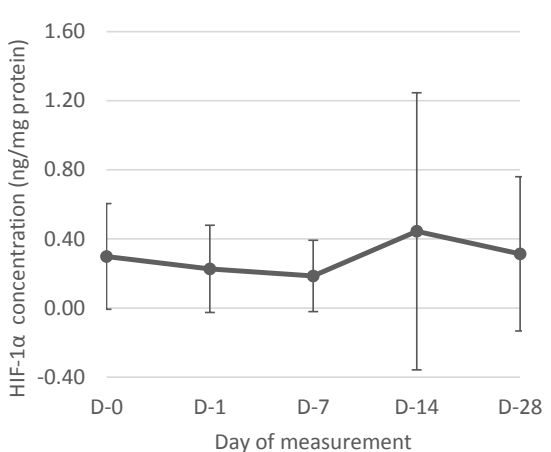

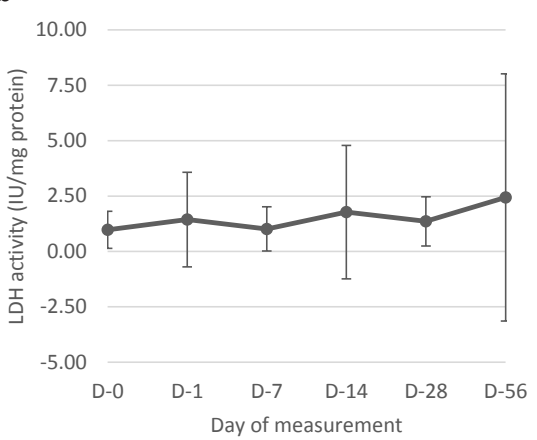

e

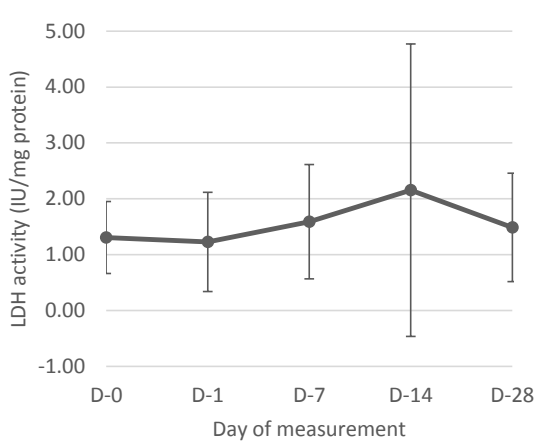

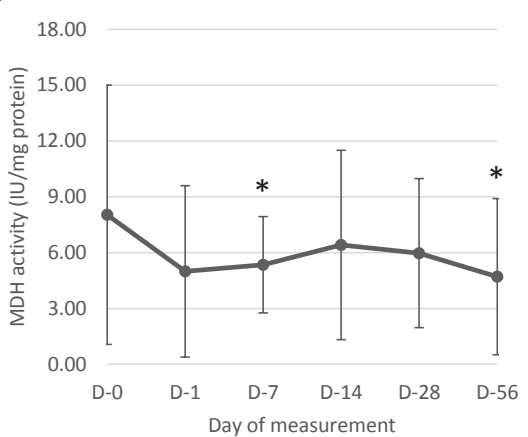

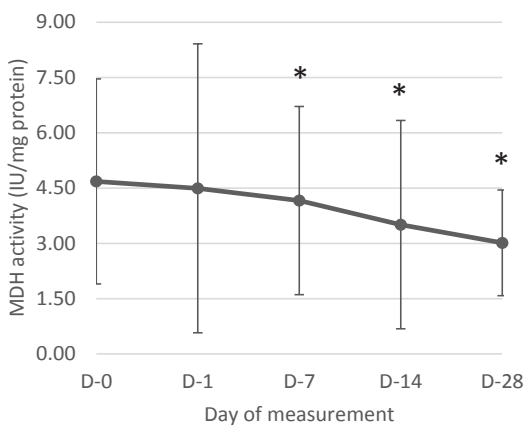

Figure 1. (a, b, c) Mean (SD) of tear HIF-1a level, LDH activity, and MDH activity in the new SCL wearer group from baseline (day o) to day 56 of SCL wear; (d, e, f) Mean (SD) of tear HIF1-a level, LDH activity, and MDH activity in long-term SCL wearers from baseline to day 28 following SCL removal. *Data was analyzed using Bonferroni post-hoc test significant based on D-o as a control $(p<0.05)$

$\mathrm{SD}=$ standard deviation; HIF-1a=hypoxia-inducible factor-1a; SCL=soft contact lens; $\mathrm{LDH}=$ lactate dehydrogenase; $\mathrm{MDH}=\mathrm{malate}$ dehydrogenase

measurements following SCL removal in the long-term wearer group $(p=0.147)$.

Positive correlations between HIF-1a concentrations and $\mathrm{MDH}$ activities were found in the long-term wearer SCL group on days 1, 14, and 28 following SCL removal. The correlation between HIF$1 a$ concentrations and MDH activities was strong and statistically significant ( $p=0.033 ; r=0.642)$.

Long-term SCL wearers had significantly higher LDH level than new SCL wearers (0.10 [0.05] versus 0.06 [0.04] IU/mg protein, respectively, $p=0.04$ ) on baseline (day 0). Comparisons of HIF-1a level and $\mathrm{MDH}$ activities between the two groups were not significant (Table 2).

We also compared HIF-1a and LDH and MDH levels between naïve eyes (the new wearer group on baseline or day 0) and long-term wearers on day 28 after SCL removal as a previous study stated that the recovery of normal epithelial oxygen uptake can be achieved 1 month after SCL wear cessation (Table 2). ${ }^{9} \mathrm{MDH}$ activities in long-term wearers on day 28 after removal were significantly lower than that in naïve eyes $(0.17[0.04-0.63]$ versus $0.34[0.2-1.98] \mathrm{IU} / \mathrm{mg}$ protein; $p=0.003)$.

\section{DISCUSSION}

HIF-1a is unstable in well-oxygenated cells and has rapid turnovers, of which the half-life is only $5 \mathrm{~min}$, which makes it difficult to be detected in conditions without hypoxia. ${ }^{9}$ Increase in HIF-1a could be an acute response to hypoxic condition whereby it would be stabilized to initiate several activation pathways to increase oxygen availability. ${ }^{11}$ In this study, tear HIF$1 a$ was relatively stable in the new wearer group for 56 days. Minimal hypoxia might still have occurred but was missed during measurement, and HIF-1a had returned to normal levels.

HIF-1a was slightly increased on day 1 in the new wearer group. It was assumed that the cornea might have had an oxygen consumption alteration, thus decreasing need and reaching a relative normoxic condition. HIF 1-a expression was an immediate response to a hypoxic condition, although the gene 
Table 2. Comparison of corneal characteristics and biomolecular activities between the new and long-term wearer groups on days 0 and 28

\begin{tabular}{|c|c|c|c|c|c|}
\hline & \multicolumn{3}{|c|}{ Day 0} & \multicolumn{2}{|c|}{ Day 28} \\
\hline & $\begin{array}{l}\text { New wearer, } \\
\text { mean (SD) }\end{array}$ & $\begin{array}{l}\text { Long-term wearer, } \\
\text { mean (SD) }\end{array}$ & $p$ & $\begin{array}{l}\text { Long-term wearer, } \\
\text { mean (SD) }\end{array}$ & $p^{*}$ \\
\hline Corneal thickness $(\mu \mathrm{m})$ & $513.21(31.63)$ & $487.25(28.21)$ & $0.002^{+}$ & $481.14(26.77)$ & $<0.001^{+}$ \\
\hline $\begin{array}{l}\text { Endothelial cell density } \\
\left(\text { cells } / \mathrm{mm}^{2} \text { ) }\right.\end{array}$ & $2961.07(227.51)$ & 2957.79 (283.97) & $0.962^{+}$ & 2876.30 (271.29) & $0.211^{+}$ \\
\hline Coefficient of variation & $41.79(5.80)$ & $44.75(6.07)$ & $0.067^{+}$ & $46.46(6.25)$ & $0.006^{+}$ \\
\hline $\begin{array}{l}\text { Hexagonality of endothelial } \\
\text { cell (\%) }\end{array}$ & $50.36(10.04)$ & $46.43(7.61)$ & $0.105^{+}$ & $43.32(8.40)$ & $0.005^{+}$ \\
\hline $\begin{array}{l}\text { HIF-1 } \alpha \text { (ng/mg protein), } \\
\text { median (min-max) }\end{array}$ & $0.26(0-1.04)$ & $0.16(0-0.86)$ & $0.89^{\ddagger}$ & $0.14(0-1.59)$ & $0.540^{\ddagger}$ \\
\hline LDH (IU/mg protein) & $0.06(0.04)$ & $0.10(0.05)$ & $0.04^{+}$ & $0.10(0.05)$ & $0.055^{+}$ \\
\hline $\begin{array}{l}\text { MDH (IU/mg protein), } \\
\text { median (min-max) }\end{array}$ & $0.34(0.20-1.98)$ & $0.38(0.06-1.43)$ & $0.51^{\ddagger}$ & $0.17(0.04-0.63)$ & $0.003^{\ddagger}$ \\
\hline
\end{tabular}

$\mathrm{SD}=$ standard deviation; HIF-1a=hypoxia-inducible factor-1a; LDH=lactate dehydrogenase; $\mathrm{MDH}=$ malate dehydrogenase *Compared to new wearers at day 0 ; ${ }^{\dagger}$-test; ${ }^{\ddagger}$ Mann-Whitney test

transcription cascade was not directly caused by inhibition of inhibitory PAS domain protein. ${ }^{12}$ In contrast, a decrease of HIF-1a on days 14 and 28 after SCL removal in long-term wearers was noted, indicating an improvement of hypoxic conditions. Moreover, HIF-1a level was lower in the long-term $S C L$ wearer group than in the new SCL wearer group during all observations that may occur due to adaptive mechanism responses to long-term $\mathrm{SCL}$ use. It also indicates that HIF-1a increases only in an acute hypoxic state. In fact, we found that HIF-1a level was lower immediately after the discontinuation of SCL wear than in new wearers in all observation periods (Figures 1, a and d). Besides the fact that it has a short half-life, we hypothesize that HIF-1a is more responsive to oxygenation from a previous hypoxic condition than just a short duration of SCL wear amid a normal preexisting condition.

$\mathrm{LDH}$ level as a marker for corneal epithelial membrane damage was stable for 56 days in the new $\mathrm{SCL}$ wearer group. It indicates that the short duration of SCL with enough oxygen transmissibility usage only caused minimal hypoxic conditions; hence, there was no damage on corneal epithelium. Continuous anaerobic metabolismin long-term SCLuse resulted in morelactate production followed by an increase of LDH enzymes. LDH would also be released because of damage or death of epithelial cells resulting from mechanic, toxic, or contact lens-associated injuries. ${ }^{11,13}$ High LDH level due to $\mathrm{SCL}$ is affected by the material, fitting type, and usage duration. However, the correlation between LDH level and oxygen transmissibility is still controversial. Ichijima and Cavanagh ${ }^{14}$ stated that LDH level was inversely proportional to the Dk value. They showed that $\mathrm{SCL}$ with low oxygen transmissibility increased the level of an anaerobic LDH subtype, indicating a metabolism shift. Imayasu et $\mathrm{al}^{15}$ showed that extended wear of SCL with very high $\mathrm{Dk}$ (total $\mathrm{Dk} / \mathrm{t}$ = 64) did not cause a significant increase in either LDH or MDH level. Meanwhile, Ladage et $\mathrm{al}^{16}$ stated that LDH levels increased only in the second week of SCL wear with high and very high oxygen transmissibility. Both groups showed similar increase of tear LDH, although there was a different SCL oxygen transmissibility. The increase in LDH under hypoxic conditions was partly due to several mechanisms, including increase of cell membrane permeability and loss of intracellular LDH bonds in epithelial cells as a response to decreased cellular energy. The synthesis of LDH de novo also contributed to increased tear LDH level. Finally, increased LDH in hydrogel contact lens wearers could also be caused by mechanical trauma to the contact lens surface. ${ }^{17}$

Tear LDH activity in long-term wearers was significantly higher than in new wearers, even after immediate SCL removal. However, decreased LDH activity was found after the discontinuation of $\mathrm{SCL}$ wear, although it did not make the LDH level in longterm wearers lower than in new wearers. Previous studies also showed that LDH tear levels in long-term 
contact lens wearers were significantly higher than those in non-contact lens wearers. ${ }^{11}$ Indeed, Ichijima et $\mathrm{al}^{18}$ proved that increased LDH due to hypoxia is reversible and reported that discontinuation of contact lens wear could restore tear LDH to the normal level.

$\mathrm{MDH}$ activity indicates the different stages of corneal damage in external eye diseases. Tear MDH is a membrane damage marker derived from the corneal and the conjunctival epithelium. An increase in tear $\mathrm{MDH}$ level was associated with contact lens-related dry eyes. ${ }^{19}$ In contrast, a decrease in tear MDH activity after SCL removal might be caused by an improvement in hypoxic and epithelial conditions, hemostasis ocular surface disorder, or contact lens-related dry eye. Fortunately, increase in $\mathrm{MDH}$ resulting from hypoxia seemed to be reversible like $\mathrm{LDH}$. In this study, there were some changes of MDH level in the new wearer group. Due to wide MDH fluctuations, it is difficult to use this clinically as a marker for corneal damage. ${ }^{19}$ Nevertheless, tear MDH activities in long-term SCL wearers had insignificant higher than those in the new wearers. Long-term mechanical trauma in contact lens wear increased MDH activities, which signal corneal and conjunctival epithelial cell membrane defects. ${ }^{19}$ This study also showed that MDH activities were associated with long-term hypoxia and gradually decreased after eliminating the causative factor, contact lens. These findings supported the reversibility of increased $\mathrm{MDH}$ activity due to hypoxia.

$\mathrm{LDH} / \mathrm{MDH}$ ratio in the new wearer group seemed to have been increasing since the first day of SCL wear. This ratio continued to increase in every subsequent observation. $\mathrm{LDH} / \mathrm{MDH}$ ratio was significantly higher after 56 days compared with baseline or day 0 ( $p=$ 0.023). In the group of long-term SCL wearers who discontinued the use of SCL, no significant changes of $\mathrm{LDH} / \mathrm{MDH}$ ratio were found at any period of measurement ( $p=0.147)$.

Corneal stress in contact lens-induced hypoxia is most commonly detected by the occurrence of limbal redness. ${ }^{15,20-23}$ Sweeney ${ }^{5}$ showed limbal redness was similar in subjects wearing contact lens with high Dk to control without SCL. This showed that only minimal hypoxia occurred in the eyes using $\mathrm{SCL}$ with good oxygen transmissibility. According to Holden and Mertz, critical oxygen transmissibility to avoid corneal edema for daily wear lenses must be at least 24 and 87 for extended wear. ${ }^{24}$ Hydrogel lenses' water content is also directly related to oxygen transmissibility, as the oxygen diffusion to the cornea occurs through the water in the lens. Hence, higher water content of SCL contributes to higher levels of oxygen. ${ }^{24}$ This corresponds with SCL used in our study, Nelfilcon A, a polyvinyl alcohol-based conventional hydrogel contact lens with Dk/t 26 at $-3.00 \mathrm{D}, 69 \%$ water content, and $0.10 \mathrm{~mm}$ thickness. ${ }^{25-27}$ This showed that SCL used in this study meets good criteria for daily wear SCL.

The limitation of this study is the process of tear sampling. HIF-1a measurement requires $200 \mu \mathrm{l}$ of tear sample from each subject, whereas LDH and $\mathrm{MDH}$ measurement requires 20 and $40 \mu$ of tears, respectively. Thus, all three tests altogether require a minimum of $260 \mu \mathrm{l}$ of tears sample from each person. However, each tear sampling could only take $150 \mu \mathrm{l}$ of tear sample. Thus, we had to perform a method that could make the respondent psychologically stimulated to produce tears. There is still a possibility that this method had caused the gap of protein content between natural and forced tears. To meet the minimum volume required, we also diluted the tear samples, which led to a lower HIF-1a concentration.

In conclusion, this study did not find any increase in HIF-1a, LDH, and MDH as biomarkers for corneal hypoxia in subjects wearing SCL for 2 months. However, there were lower $\mathrm{LDH}$ and $\mathrm{MDH}$ tears activities after discontinuation of SCL wear.

\section{Conflicts of Interest}

The authors affirm no conflict of interest in this study.

\section{Acknowledgment \\ None.}

\section{Funding Sources}

This study was partially funded by Hibah Riset UI 2015, in the scheme of Hibah Riset Pascasarjana from the Directorate of Research and Community Engagement of Universitas Indonesia (DRPM UI).

\section{REFERENCES}

1. Lim CHL, Stapleton F, Mehta JS. Review of contact lens-related complications. Eye Contact Lens. 2018;44 Suppl 2:S1-10.

2. Moreddu R, Vigolo D, Yetisen AK. Contact lens technology: from fundamentals to applications. Adv Healthc Mater. 2019;8(15):e1900368.

3. Nichols JJ, Willcox MD, Bron AJ, Belmonte C, Ciolino JB, Craig $J P$, et al. The TFOS international workshop on contact lens discomfort: executive summary. Invest Ophthalmol Vis Sci. 2013;54(11):TFOS7-13.

4. Galas S, Copper LL. Oxygen permeability of the pigmented material used in cosmetic daily disposable contact lenses. Clin Ophthalmol. 2016;10:2469-74.

5. Sweeney DF. Clinical signs of hypoxia with high-Dk soft lens extended wear: is the cornea convinced? Eye Contact Lens. 2003;29(1 Suppl):S22-5; discussion S26-9, S192-4.

6. Papas EB. The significance of oxygen during contact lens wear. 
Cont Lens Anterior Eye. 2014;37(6):394-404

7. Lee SE, Kim SR, Park M. Influence of tear protein deposition on the oxygen permeability of soft contact lenses. J Opthalmol. 2017;2017:5131764.

8. Magdum RM, Mutha N, Maheshgauri R. A study of corneal endothelial changes in soft contact lens wearers using non-contact specular microscopy. Med J DY Patil Univ. 2013;6(3):245-9.

9. Holden BA, Sweeney DF, Vannas A, Nilsson KT, Efron N. Effects of long-term extended contact lens wear on the human cornea. Invest Ophthalmol Vis Sci. 1985;26(11):1489-501.

10. Koyasu S, Kobayashi M, Goto Y, Hiraoka M, Harada H. Regulatory mechanisms of hypoxia-inducible factor 1 activity: two decades of knowledge. Cancer Sci. 2018;109(3):560-71.

11. Sweeney DF. Have silicone hydrogel lenses eliminated hypoxia? Eye Contact Lens. 2013;39(1):530-60.

12. Semenza GL. Regulation of cancer cell metabolism by hypoxiainducible factor 1. Semin Cancer Biol. 2009;19(1):12-6.

13. Lahagu EA, Fachiroh J, Anugrah AS, Gunawan W, Mahayana IT, Suhardjo. Changes of lactate dehydrogenase in corneal edema after cataract surgery treated with trans-corneal oxygenation therapy. Int J Ophthalmol. 2020;13(7):1148-51.

14. Ichijima H, Cavanagh HD. Effects of rigid lens extended wear on lactate dehydrogenase activity and isozymes in rabbit tears. Cornea. 1994;13(5):429-34.

15. Imayasu M, Petroll WM, Jester JV, Patel SK, Ohashi J, Cavanagh HD. The relation between contact lens oxygen transmissibility and binding of Pseudomonas aeruginosa to the cornea after overnight wear. Ophthalmology. 1994;101(2):371-88.

16. Ladage PM, Yamamoto K, Ren DH, Li L, Jester JV, Petroll WM, et al. Effects of rigid and soft contact lens daily wear on corneal epithelium, tear lactate dehydrogenase, and bacterial binding to exfoliated epithelial cells. Ophthalmology. 2001;108(7):127988.
17. Azuma M, Shi M, Danenberg KD, Gardner H, Barrett $C$, Jacques $\mathrm{CJ}$, et al. Serum lactate dehydrogenase levels and glycolysis significantly correlate with tumor VEGFA and VEGFR expression in metastatic CRC patients. Pharmacogenomics. 2007;8(12):1705-13.

18. Ichijima H, Imayasu M, Ohashi J, Cavanagh HD. Tear lactate dehydrogenase levels. A new method to assess effects of contact lens wear in man. Cornea. 1992;11(2):114-20.

19. Guo Q, Huang H, Pi Y, Zhang H. Evaluation of tear malate dehydrogenase 2 in mild dry eye disease. Eye Sci. 2014;29(4):204-8.

20. Beljan J, Beljan K, Beljan Z. Complications caused by contact lens wearing. Coll Antropol. 2013;37 Suppl 1:179-87.

21. Efron N. Contact lens wear is intrinsically inflammatory. Clin Exp Optom. 2017;100(1):3-19.

22. Sapkota K, Franco S, Lira M. Daily versus monthly disposable contact lens: which is better for ocular surface physiology and comfort? Cont Lens Anterior Eye. 2018;41(3):252-7.

23. Szczotka-Flynn LB, Debanne S, Benetz BA, Wilson T, Brennan $\mathrm{N}$. Daily wear contact lenses manufactured in Etafilcon $A$ are noninferior to two silicone hydrogel lens types with respect to hypoxic stress. Eye Contact Lens. 2018;44(3):190-9.

24. Samira CP, Rahayu T, Kekalih A. Comparison of corneal thickness and endothelial cell morphology in myopic patients with daily wear hydrogel (Nelfilon A) and silicon hydrogel (Lotrafilcon B) contact lenses: a pilot study. Ophthalmol Ina. 2016;42(3):283-8.

25. Efron N, Brennan NA, Chalmers RL, Jones L, Lau C, Morgan PB, et al. Thirty years of 'quiet eye' with etafilcon A contact lenses. Cont Lens Anterior Eye. 2020;43(3):285-97.

26. Lee SE, Kim SR, Park M. Oxygen permeability of soft contact lenses in different $\mathrm{pH}$, osmolality and buffering solution. Int $J$ Ophthalmol. 2015;8(5):1037-42.

27. Musgrave CSA, Fang F. Contact lens materials: a materials science perspective. Materials (Basel). 2019;12(2):261 